\title{
Comparative Study of Physical Properties of In-Use Surfactant-Grafted Polyacrylamides for Oilfield
}

\author{
Tingting Jiang1, Haiyu Wang2, Baohui Wang1 \\ ${ }^{1}$ Institute of New Energy Chemistry and Environmental Science, College of Chemistry \& Chemical Engineering, \\ Northeast Petroleum University, Daqing, China \\ ${ }^{2}$ First Oil Plant, Daqing Oilfield Company Limited, Daqing, China \\ Email: jiangtingting82@163.com
}

Received 10 June 2014; revised 5 July 2014; accepted 30 July 2014

Copyright (C) 2014 by authors and Scientific Research Publishing Inc.

This work is licensed under the Creative Commons Attribution International License (CC BY).

http://creativecommons.org/licenses/by/4.0/

c) (i) Open Access

\begin{abstract}
Surfactant-grafted Polyacrylamide (S-PAM), as a new type of oil displacement agent in oilfield, integrates the advantages of both polymer and surfactant. The oil displacement experiments using S-PAM in multi-blocks reveal that in-use S-PAMs differ greatly from ordinary polymers and the physical properties remain unclear. This is unfavorable to production application and occupational health and safety. This research compared the physical properties of S-PAMs selected from two producing area, including specific gravity, particle size and viscosity. The compared results showed that specific gravity of Lianhua S-PAM was smaller than Haibo S-PAM; Lianhua S-PAM and Haibo S-PAM accounted for the $\mathbf{9 3 . 8 \%}$ and $\mathbf{8 0 . 1 \%}$ of the total amount via the particles with 40 mesh and 60 mesh; the viscosity of Lianhua S-PAM was higher than that of Haibo S-PAM in two $S$-PAM solutions with different concentrations.
\end{abstract}

\section{Keywords}

Surfactant-Grafted Polyacrylamide, Physical Properties, Comparative, Oilfield

\section{Introduction}

Polymer flooding is a tertiary oil recovery technique which was developed in 1960s. It is able to highly improve the recovery factor and a more economical and efficient monadic chemical flooding [1]-[3]. Its characteristic is to add the polymer with high molecular weight into water, so that the viscosity of water and mobility ratio of displacing phase and displaced phase can be improved to increase oil recovery factor by expanding swept vo- 
lume. In USA, polymer flooding was applied in later 1950s. While its related filed tests were carried out in middle 1960s; in 1970s, polymer filed tests were performed by the Former Soviet Union, Canada, UK, France, Romania and Germany in succession. Owing to the favorable characteristics of polymer flooding including less complex mechanism, simple technique and low cost etc., it is more suitable for applying in most of oilfields in China. Daqing oilfield conducted polymer flooding field test in 1972. Presently, the polymer flooding has been an important technique ensuring the high and stable yield of Daqing oilfield [4]-[6].

In oil exploitation, water-soluble polymer surfactant is usually adopted to improve recovery factor. However, ordinary polymer surfactants are restricted by their poor temperature resistance and salt resistance in deep oil reservoir, high temperature in oil well and high salinity in tertiary oil recovery. This research proposed the surfactant-grafted polyacrylamides. In water soluble process, the association of hydrophobic segment was found. On the condition of high temperature and high salinity, due to the association, the S-PAM solution leads to that viscosity increases with the increasing concentration of electrolyte and rising temperature [7]-[10].

This study analyzed the physical properties of Lianhua S-PAM and Haibo S-PAM comparatively using chemical analysis method and instrument analysis method etc.

\section{Experiments}

\subsection{Materials and Instruments}

Two S-PAMs used in this experiment were: Daqing Refining \& Chemical Company S-PAM (Lianhua type III), which is called Lianhua S-PAM in the research; Shanghai Haibo company S-PAM (Haibo type III), which is called Haibo S-PAM; the instrument used in the experiment was Brookfield viscometer LVDV-II.

\subsection{Methods}

\subsubsection{Determination of Specific Gravity}

The specific gravity is also called relative density, namely, density ratio. It is a ratio of determining substances' density to the density of water without unit. The experiment employed the bulk density of S-PAM solid particles. With water density of $1000 \mathrm{~kg} / \mathrm{m}^{3}$, based on the definition of specific gravity (specific = density $/ 1000 \mathrm{~kg} / \mathrm{m}^{3}$ ), the specific gravity of two S-PAMs can be obtained. The surfactants A and B were conducted five groups of tests, by taking average value, the specific gravity of two surfactants were acquired.

\subsubsection{Determination of Particle Size}

In this experiment, a sieving method was used to determine the particle size of two S-PAMs as follows:

1) A set of screens were selected and put on the oscillator according to the sizes of meshes from up to bottom.

2) The S-PAM sample of $100 \mathrm{~g}$ was measured and poured on the upper sieving layer, by covering it using sieve cove and fixing the whole set of sieves, the oscillator was started up as starting the timer. The oscillation and screen were conducted for a certain period.

3) By stopping the oscillation and screen, taking off the sieving cap, each screen was taken off in turn. Afterwards, the masses of each screen were measured and compared with that of empty screen. To reduce errors, each sample was conducted two tests.

\subsubsection{The Determination of Viscosity}

Brookfield viscometer LVDV-II was used to measure the viscosities of the fresh water prepared S-PAM solution of $1200 \mathrm{mg} / \mathrm{L}$, the sewage prepared S-PAM solution of $1200 \mathrm{mg} / \mathrm{L}$ and the S-PAM mother solution of 3000 $\mathrm{mg} / \mathrm{L}$.

\section{Results and Discussion}

\subsection{The Appearance Description}

In solid state, the Lianhua S-PAM was white granular substance; while Haibo S-PAM was slightly light yellow granular substance. By putting S-PAM particles on the paper surface for a while, the oil like substance leached was found. In addition, Lianhua S-PAM showed viscosity S-PAM B in preparation of S-PAM solution with a certain concentration; in mixing process, Lianhua S-PAM is more likely to generate bubbles than that of Haibo. 


\subsection{Determination of Specific Gravity}

Lianhua S-PAM and Haibo S-PAM were conducted five groups of test respectively. By employing the average, the specific gravities of two S-PAMs could be obtained; the experimental results are shown in Table 1 and Table 2.

By calculating the average of the density $\rho$ in Table 1 and Table 2, the densities of S-PAMs are listed in Table 3.

The water density is $1000 \mathrm{~kg} / \mathrm{m}^{3}$, the specific gravity of two S-PAMs can be acquired based on the definition of specific gravity (specific $=$ density $/ 1000 \mathrm{~kg} / \mathrm{m}^{3}$, unit: $\mathrm{kg} / \mathrm{m}^{3}$ ) as Table 4 .

\subsection{The Determination of Particle Size}

Particle size is defined as the size and distribution of solid particle. It denotes the percentage of particle mass in the mass of total samples with a range of particle size. The research employed a sieving method to measure the size of S-PAM particle. The principle of using sieving method to measure the particle size is described as:

The dimensions of particle and its distribution (particle size) were determined using a series of screens with varied mesh sizes. Then, the screens were well folded form up to bottom in turn according to the decreasing order of mesh diameters. The sample to be determined was poured from upper end. By covering the sieve, the whole set of screens were fixed to oscillate on the oscillator. The samples were screened using a series of screens, then collected from each screen. By measuring the mass of each screen before and after test, the mass of the material on the screen can be acquired. Taking the particle size as the percentage of the particle mass in a certain size range, the formula is as follows.

$$
D=\frac{m-m^{\prime}}{m} \times 100
$$

where $D$ refers to the particle size of samples; $m$ denotes the mass of sample (unit: $g$ ); $m$ ' is the mass of samples which fail to pass through the screen with some pore diameter (unit: g). The particle size distribution results are shown in Table 5 and Table 6.

\subsection{Determination of Viscosity}

Brookfield viscometer LVDV-II was adopted to determine the viscosities of the fresh water prepared S-PAM solution of $1200 \mathrm{mg} / \mathrm{L}$, the sewage prepared S-PAM solution of $1200 \mathrm{mg} / \mathrm{L}$ and the S-PAM mother solution of 3000 mg/L.

Table 1. The bulk density of Lianhua S-PAM.

\begin{tabular}{cccccc}
\hline $\mathrm{V}(\mathrm{mL})$ & 2.15 & 4.08 & 6.11 & 8.05 & 9.95 \\
$\mathrm{~m}(\mathrm{~g})$ & 1.3153 & 2.5202 & 3.9368 & 5.3063 & 6.5207 \\
$\rho(\mathrm{g} / \mathrm{mL})$ & 0.612 & 0.618 & 0.644 & 0.659 & 0.655 \\
\hline
\end{tabular}

Table 2. The bulk density of Haibo S-PAM.

\begin{tabular}{cccccc}
\hline $\mathrm{V}(\mathrm{mL})$ & 2.10 & 4.08 & 5.90 & 7.80 & 9.60 \\
$\mathrm{~m}(\mathrm{~g})$ & 1.3479 & 2.5704 & 3.9019 & 5.3056 & 6.6074 \\
$\rho(\mathrm{g} / \mathrm{mL})$ & 0.642 & 0.630 & 0.661 & 0.680 & 0.688 \\
\hline
\end{tabular}

Table 3. The densities of S-PAMs.

\begin{tabular}{cl}
\hline Density of Lianhua S-PAM $(\mathrm{g} / \mathrm{mL})$ & 0.6376 \\
Density of Haibo S-PAM $(\mathrm{g} / \mathrm{mL})$ & 0.6602 \\
\hline \multicolumn{2}{c}{ Table 4. The specific gravity of S-PAMs. } \\
\hline Specific gravity of Lianhua S-PAM & 0.6376 \\
Specific gravity of Haibo S-PAM & 0.6602 \\
\hline
\end{tabular}


The field investigations showed that there were two dilution methods in the preparation of S-PAM solution: S-PAM mother solutions were transferred to single well after diluting by fresh water and sewage to a certain concentration respectively. The viscosities of the solutions diluted using two abovementioned methods were measured according to in situ temperature. The results are presented in Table 7. Owing to viscosity associates closely with size, shape and rotating speed of rotor, and the temperature of solution, the following information require to be presented in the illustration of determined viscosity results.

Viscosity results determined suggest that the viscosity of Lianhua S-PAM solution is higher than that of Haibo in terms of both S-PAM mother solution of $3000 \mathrm{mg} / \mathrm{L}$ and the mother solution prepared S-PAM solution of $1200 \mathrm{mg} / \mathrm{L}$. In addition, the comparison of viscosities of S-PAM solutions prepared by fresh water at $15.3^{\circ} \mathrm{C}$ and sewage at $45.5^{\circ} \mathrm{C}$ reveals that preparation of S-PAM solution at higher temperature can greatly reduce the viscosity of solution.

\subsection{The Comparison of Physical Properties}

On the basis the research results above mentioned, unlike traditional polymer, multi-constitutes S-PAM is a new oil displacement polymer which is formed by multi-constitutes graft copolymerization with flexible hydrocarbon chain as the frame based on interactions of molecules. Its structure is shown in Figure 1.

Where $\mathrm{X}$, Y refer to -- $\mathrm{HZ}$, --ONa, --OR, --HR, -- $\mathrm{RSO}_{3} \mathrm{Na}$, --: the surfactants of quaternary ammonium salt, --(EO)n(PO)Mr, --: cationic Gemini, and -RSH. Lianhua S-PAM refining factory polymerized the nonionic and cationic surfactants, while that Haibo S-PAM polymerized the nonionic surfactants on the main chain of polyacrylamide. Moreover, the functional groups of the two S-PAM are different. Different surfactants copolymerized on the main chains of two S-PAMs lead to the varied $\mathrm{f}$ physical properties.

\section{Conclusions}

Comparative study of the physical properties of S-PAM implied that, specific gravity of Lianhua S-PAM was

Table 5. The particle size of Lianhua S-PAM.

\begin{tabular}{ccccc}
\hline Mesh number & 20 & 40 & 60 & 80 \\
\hline Experiment 1 & 2.5 & 62.3 & 30.0 & 6.1 \\
Experiment 2 & 2.2 & 63.6 & 31.6 & 2.8 \\
Particle size & $2.4 \%$ & $63.0 \%$ & $30.8 \%$ & $4.5 \%$ \\
\hline
\end{tabular}

Table 6. The particle size of Haibo S-PAM.

\begin{tabular}{ccccc}
\hline Mesh number & 20 & 40 & 60 & 80 \\
\hline Experiment 1 & 19.8 & 54.5 & 25.4 & 0.7 \\
Experiment 2 & 12.2 & 54.8 & 25.3 & 8.2 \\
Particle size & $16.0 \%$ & $54.7 \%$ & $25.4 \%$ & $4.5 \%$ \\
\hline
\end{tabular}

Table 7. Viscosity results determined of S-PAM solution.

\begin{tabular}{|c|c|c|c|c|c|}
\hline Name & $\begin{array}{c}\text { Concentration } \\
\text { (mg/L) }\end{array}$ & $\begin{array}{c}\text { Temperature } \\
\left({ }^{\circ} \mathrm{C}\right)\end{array}$ & $\begin{array}{l}\text { The type of } \\
\text { rotor }\end{array}$ & $\begin{array}{l}\text { Rotating speed } \\
\text { (RPM) }\end{array}$ & $\begin{array}{l}\text { Viscosity } \\
\text { (cP) }\end{array}$ \\
\hline Fresh water prepared S-PAM (Lianhua) & 1200 & 15.3 & LV-2 & 30 & 306.9 \\
\hline Fresh water prepared S-PAM (Haibo) & 1200 & 15.3 & LV-2 & 30 & 158.0 \\
\hline Sewage prepared S-PAM ( Lianhua) & 1200 & 45.5 & LV-1 & 30 & 30.8 \\
\hline Sewage prepared S-PAM (Haibo) & 1200 & 45.5 & LV-1 & 60 & 19.3 \\
\hline S-PAM mother solution (Lianhua) & 3000 & 15.7 & LV-3 & 6 & 3179 \\
\hline S-PAM mother solution (Haibo) & 3000 & 14.6 & LV-3 & 6 & 2739 \\
\hline
\end{tabular}




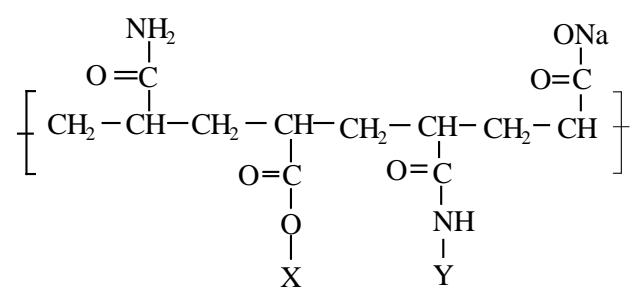

Figure 1. Molecular structure of S-PAM.

smaller than Haibo S-PAM; Lianhua S-PAM and Haibo S-PAM accounted for the 93.8\% and $80.1 \%$ of the total amount via the particles with 40 mesh and 60 mesh; the viscosity of Lianhua S-PAM was higher than that of Haibo S-PAM in two S-PAM solutions with different concentrations.

\section{References}

[1] Wang, D.M., Xia, H.F., Liu, Z.C., et al. (2001) Study of the Mechanism of Polymer Solution with Viscoelastic Behaviour Increasing Microscopicoil Displacement Efficiency and the Forming of Steady "Oil Thread” Flow Channel. SPE68732, Society of Petroleum Engineers.

[2] Hu, B.Z. (1997) Production Engineering of Polymer Flooding. Petroleum Industry Press, Beijing, 70-72.

[3] Ge, G.Z., Wang, J.Y. and Wang, Y.L. (2001) Polymer Flooding and Related Chemical Flooding Progress. Oilfield Chemistry, 18, 282-284.

[4] Parrish, B., Breitenkamp, R.B. and Emrick, T. (2005) PEG- and Peptide-Grafted Aliphatic Polyesters by Click Chemistry. Journal of the American Chemical Society, 127, 7404-7410. http://dx.doi.org/10.1021/ja050310n

[5] Li, H.Y., Jérôme, R., Lecomte, Ph., et al. (2007) Combination of Ring-Opening Polymerization and “Click” Chemistry for the Synthesis of an Amphiphilic Tadpole-Shaped Poly( $\varepsilon$-Caprolactone) Grafted by PEO. Macromolecules, 40, 824831. http://dx.doi.org/10.1021/ma062488f

[6] Zhang, J.Y., Zhou, Y.M., Liu, S.Y., et al. (2008) Polyion Complex Micelles Possessing Thermoresponsive Coronas and Their Covalent Core Stabilization via “Click” Chemistry. Macromolecules, 41, 1444-1454. http://dx.doi.org/10.1021/ma702199f

[7] Luo, X.L., Wang, G.W., Huang, J.L., et al. (2008) Synthesis of a Novel Kind of Amphiphilic Graft Copolymer with Miktoarm Star-Shaped Side Chains. Macromolecules, 41, 2315-2317. http://dx.doi.org/10.1021/ma800117d

[8] Hizal, G., Tunca, U., Yagci, Y., et al. (2006) Anthracene-Maleimide-Based Diels-Alder “Click Chemistry” as a Novel Route to Graft Copolymers. Macromolecules, 39, 5330-5336. http://dx.doi.org/10.1021/ma060690c

[9] Wang, Y.M., Wang, Y.J. and Lu, X.B. (2008) “Grafting-From” Polymerization for Uniformly Bulk Modification of Pre-Existing Polymer Materials via a Supercritical-Fluid Route. Polymer, 49, 474-480. http://dx.doi.org/10.1016/j.polymer.2007.11.028

[10] Zhao, J.R., Li, J.Y., Feng, Y., et al. (2007) A Novel Approach to Synthesis of Functional CPVC and CPE or Graft Copolymers-In Situ Chlorinating Graft. Polymers for Advanced Technologies, 18, 822-828. http://dx.doi.org/10.1002/pat.941 
Scientific Research Publishing (SCIRP) is one of the largest Open Access journal publishers. It is currently publishing more than 200 open access, online, peer-reviewed journals covering a wide range of academic disciplines. SCIRP serves the worldwide academic communities and contributes to the progress and application of science with its publication.

Other selected journals from SCIRP are listed as below. Submit your manuscript to us via either submit@scirp.org or Online Submission Portal.
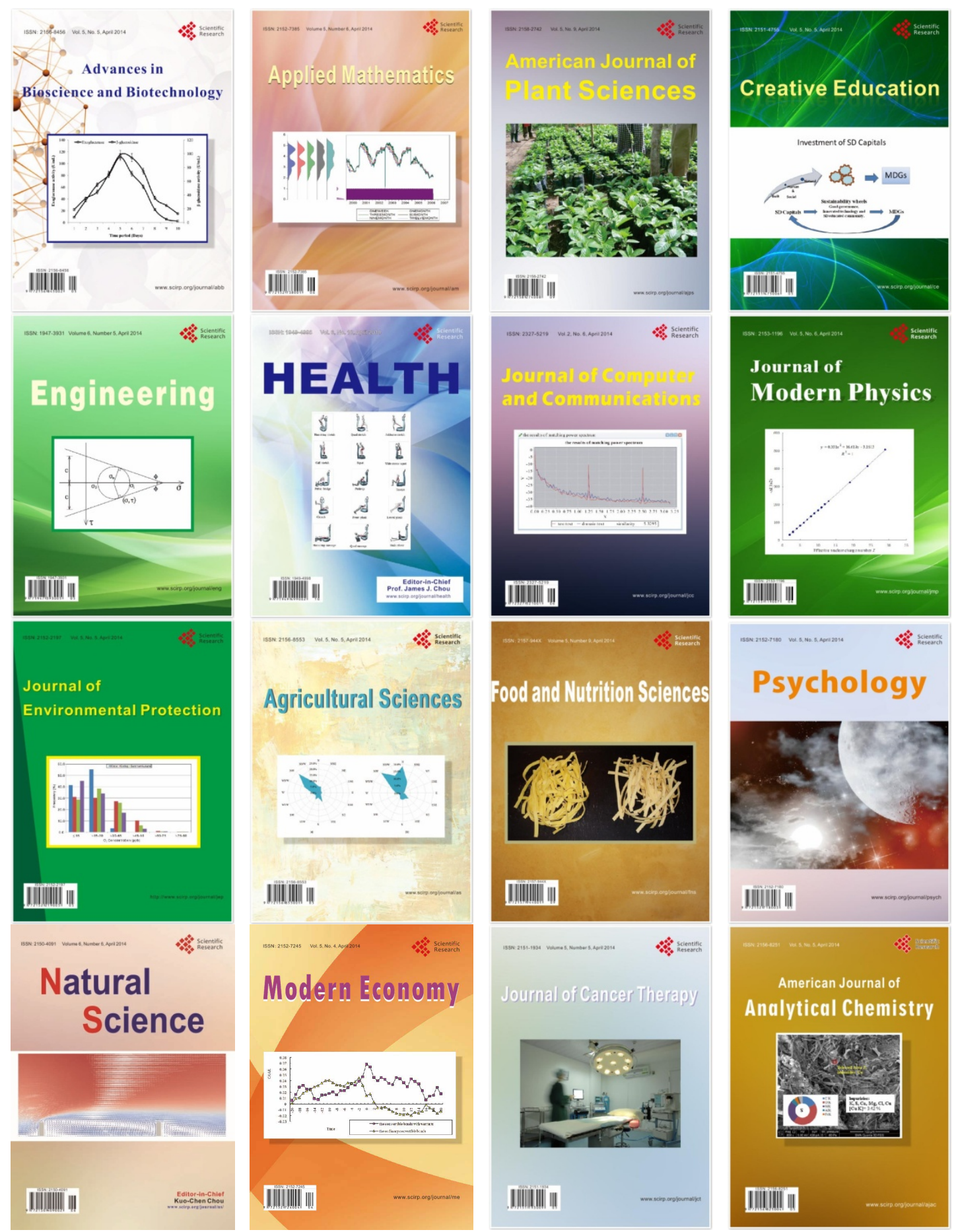